\title{
Does the wind turbine wake follow the topography? A multi-lidar study in complex terrain
}

\author{
Robert Menke $^{1}$, Nikola Vasiljević ${ }^{1}$, Kurt S. Hansen ${ }^{2}$, Andrea N. Hahmann ${ }^{1}$, and Jakob Mann ${ }^{1}$ \\ ${ }^{1}$ Technical University of Denmark - DTU Wind Energy, \\ Fredriksborgvej 399, Building 118, 4000 Roskilde, Denmark \\ ${ }^{2}$ Technical University of Denmark - DTU Wind Energy, \\ Nils Koppels Allé, Building 403, 2800 Kgs. Lyngby, Denmark \\ Correspondence: Robert Menke (rmen@dtu.dk)
}

Received: 3 March 2018 - Discussion started: 27 March 2018

Revised: 13 August 2018 - Accepted: 24 August 2018 - Published: 10 October 2018

\begin{abstract}
The wake of a single wind turbine in complex terrain is analysed using measurements from lidars. A particular focus of this analysis is the wake deficit and propagation. Six scanning lidars (three short-range and three long-range WindScanners) were deployed during the Perdigão 2015 measurement campaign, which took place at a double-ridge site in Portugal. Several scanning scenarios, including triple- and dual-Doppler scans, were designed to capture the wind turbine wake of a $2 \mathrm{MW}$ turbine located on one of the ridges. Different wake displacements are categorized according to the time of the day. The results show a strong dependence of the vertical wake propagation on the atmospheric stability. When an atmospheric wave is observed under stable conditions, the wake follows the terrain down the ridge with a maximum inclination of $-28^{\circ}$. During unstable conditions, the wake is advected upwards by up to $29^{\circ}$ above the horizontal plane.
\end{abstract}

\section{Introduction}

Detailed knowledge about the behaviour of wind turbine wakes is essential for the design and the operation of wind farms. The wake is a region of reduced wind speed and increased turbulence in the downwind direction behind a wind turbine. It is caused by the extraction of kinetic energy from the wind field. As the wake propagates, it can affect other turbines in the downwind direction, which will produce less power due to the reduced kinetic energy of the flow (Barthelmie et al., 2007). Additionally, higher turbulence levels in the wake cause high fatigue loads, which in turn reduce the lifetime of wind turbines (Bustamante et al., 2015; Thomsen and Sørensen, 1999). Due to these facts and the trend to erect turbines in wind farms where turbines are relatively closely packed together, a detailed understanding of the wake propagation is imperative. Frequently applied computer models in the wind farm planning process include simplifications that are acceptable for sites with a simple orography. For example, the linearized model of the Wind Atlas Analysis and Application Program (WAsP) assumes that the wake follows the shape of the terrain in the downstream direction (Troen and Petersen, 1989). More sophisticated approaches like computational fluid dynamics (CFD) models and large eddy simulations (LESs), do not constrain the wake propagation but cover prevailingly neutral atmospheric conditions apart from few academic studies (e.g. convective instabilities: Mirocha et al., 2014; stable conditions: Aitken et al., 2014; Bhaganagar and Debnath, 2015; both convective and stable: Mirocha et al., 2015; Vollmer et al., 2016; Abkar and Porté-Agel, 2015; Englberger and Dörnbrack, 2017). To investigate to which degree these assumptions and limitations are applicable to real flow cases, we performed a fullscale experiment in complex terrain using wind lidars.

Wind lidars are available as continuous wave $(\mathrm{CW})$ or pulsed systems. CW lidars are capable of providing highfrequency measurements of the line-of-sight (LOS) speed (up to $400 \mathrm{~Hz}$, Vasiljević et al., 2017). However, at any given measurement rate $\mathrm{CW}$ lidars can only measure the LOS speed from a single range. Since the range determination is achieved by focusing the laser beam on a given point, the 
probe length is not constant with range. In fact, the probe length increases with the square of the range (Mikkelsen et al., 2008). This limits the maximum range of current $\mathrm{CW}$ lidars to about $150 \mathrm{~m}$. Nevertheless, their capability of observing the wind field with a high frequency and relatively small probe lengths makes them ideal for studies of both mean and turbulent properties of the near wake in a region of up to two rotor diameters such as performed by Bingöl et al. (2010) and Trujillo et al. (2011). Unlike CW lidars, pulsed lidars can simultaneously measure LOS wind speeds from a number of ranges e.g., several hundred ranges in the case of the long-range WindScanner (Vasiljević et al., 2016), while their probe length is constant. The typical probe length is $30 \mathrm{~m}$. Depending on their design, pulsed lidars can achieve a measurement range of up to $12 \mathrm{~km}$ (Krishnamurthy et al., 2013). However, pulsed lidars have a lower measurement rate than CW lidars (typically around $1 \mathrm{~Hz}$ ). Due to the aforementioned characteristics, pulsed lidars are suitable for observations of the mean properties of the flow over larger distances and are used to study the far wake of wind turbines (i.e. Käsler et al., 2010; Iungo and Porté-Agel, 2013).

To the knowledge of the authors, the wake behaviour in highly complex terrain has not been investigated. All existing investigations of wakes with lidars took place in flat or moderately complex terrain and offshore (Bingöl et al., 2008; Rhodes and Lundquist, 2013; Smalikho et al., 2013; Aitken and Lundquist, 2014; Vollmer et al., 2015; Machefaux et al., 2016; Herges et al., 2017; Bodini et al., 2017). The present study focuses on wake measurements of a turbine located in highly complex terrain. During the Perdigão 2015, campaign which was a precursor for the larger Perdigão 2017 campaign (Witze, 2017), the wake of a single wind turbine located on one of two parallel ridges was scanned. The terrain is characterized by patchy vegetation and a steep orography. For this purpose, six scanning lidars were deployed during a field campaign in the late spring and early summer of 2015 , which is a part of a series of atmospheric experiments for wind energy (Mann et al., 2017). Three of the six lidars are longrange WindScanner (LRWS) pulsed Doppler lidars (Vasiljevic, 2014; Vasiljević et al., 2016) and three are short-range WindScanner (SRWS) CW wave lidars (Mikkelsen et al., 2008). The WindScanner system allows for the measurement of synchronized trajectories; thereby, the retrieval of all three wind components is possible. The combination of both systems allows measuring the near and far wake, which is a novelty for wake measurements. The measurement analysis is concentrated on the vertical wake propagation and its relation to atmospheric stability. This dependency is of particular interest for turbines located in complex terrain in regions that are subject to strong radiative forcings, e.g. the Mediterranean region. In these regions, the atmosphere is normally stable during the night and unstable during the day.

The paper is organized as follows. An overview of the designed scanning trajectories and a general description of the campaign is presented in Sect. 2. In Sect. 3 the available data and methods of their processing are introduced. Moreover, a new method to determine the inflow velocity in complex terrain is presented. Section 4 presents the results of the wake deficit analysis and wake propagation investigation. A summary and the conclusions of this work are given in the last section.

\section{Field campaign overview}

The Perdigão 2015 field campaign took place during the months of May and June 2015. The site was selected to meet several scientific objectives. A detailed overview of the entire campaign is presented in Vasiljević et al. (2017). In this section, we give a summary of the campaign and site characteristics relevant for the measurements of the wind turbine wake.

\subsection{Measurement site}

The main characteristic of the site are two ridges that run in parallel for a distance of $2 \mathrm{~km}$ (Figs. 1 and 2). The ridge to ridge distance is about $1.4 \mathrm{~km}$, and the valley bottom to ridge peak height equals about $200 \mathrm{~m}$. The ridges run from the southeast towards the northwest. The orography is generally lower to the northeast and southwest. The roughness of the terrain is determined by rocks and patchy vegetation of pine and eucalyptus trees. A previous 3-year assessment of the wind conditions by a $40 \mathrm{~m}$ high meteorological mast located on the southwest ridge about $1 \mathrm{~km}$ in the southwest of the wind turbine shows two prevailing wind directions: northeast and southwest. These wind directions are perpendicular to the ridges. The wake measurements are obtained for a single Enercon E-82 $2 \mathrm{MW}$ wind turbine located on the southwest ridge (see Fig. 2). This turbine has a hub height of $78 \mathrm{~m}$ and a rotor diameter of $82 \mathrm{~m}$. It is designed as a low wind-speed turbine with a cut-in wind speed of $2 \mathrm{~m} \mathrm{~s}^{-1}$. The terrain around the turbine drops of several tens of metres towards the southwest. Towards the northeast, the terrain slants down towards the valley after a smaller escarpment of about $20 \mathrm{~m}$ height.

\subsection{WindScanner measurements}

Two WindScanner systems were deployed in the Perdigão 2015 campaign: a short-range and a long-range WindScanner systems consisting of three short-range lidars and three long-rage lidars, respectively. The short-range system was positioned close to the turbine, considering the shorter range and the probe volume size. For the SRWS the probe length increases quadratically with the measurement distance from about $0.2 \mathrm{~m}$ at $10 \mathrm{~m}$ to $40 \mathrm{~m}$ at $150 \mathrm{~m}$. Consequently, to keep the spatial averaging small, a measurement scenario is designed to measure the near wake of the turbine. The scenario consists of a vertical plane, perpendicular to the turbine transect in the northeast of the 
(a)

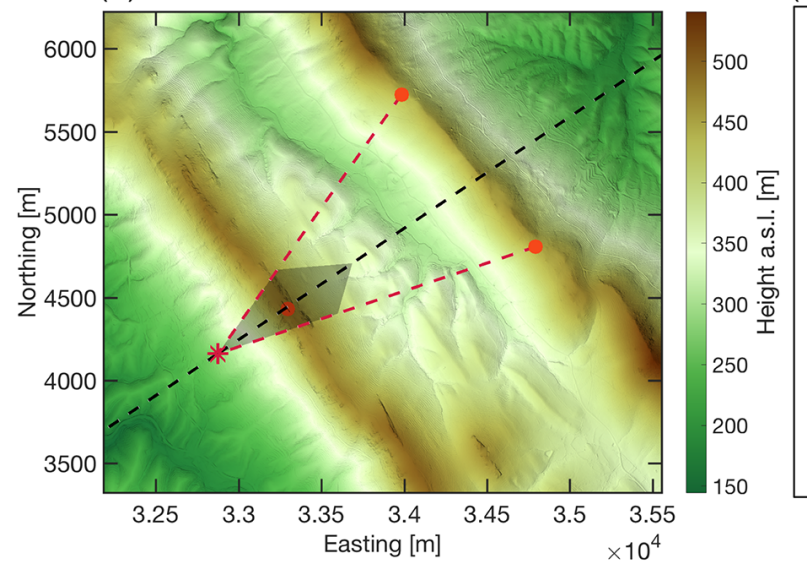

(b)

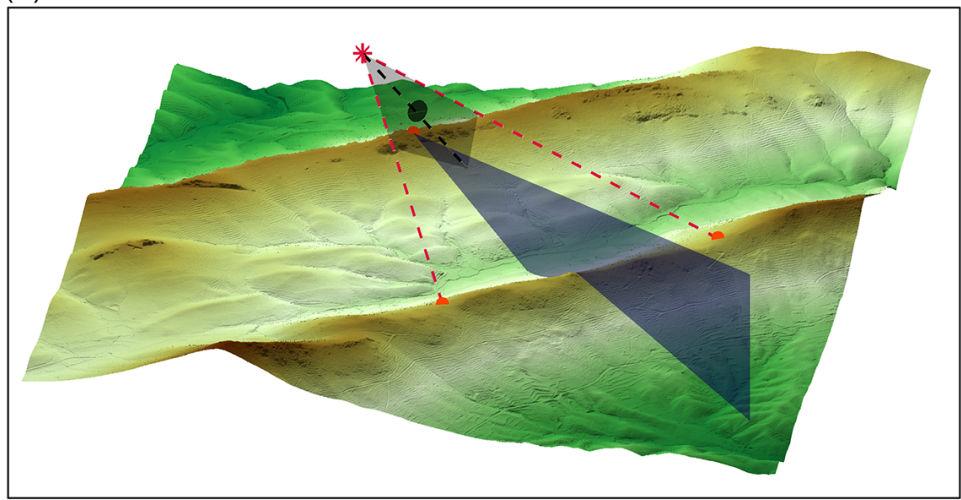

Figure 1. Overview of the terrain and scanning trajectories. Coordinates expressed in ETRS89/PTM06 and height above sea level. Red points: location of long-range WindScanners; blue plane: RHI scan; black circle: rotor plane; black plane: diamond scan plane; black dashed line: wind turbine transect or line of synchronized measurements in diamond scan; red dashed line: example of beams doing a measurement. Panel (a): top view; panel (b): tilted view.

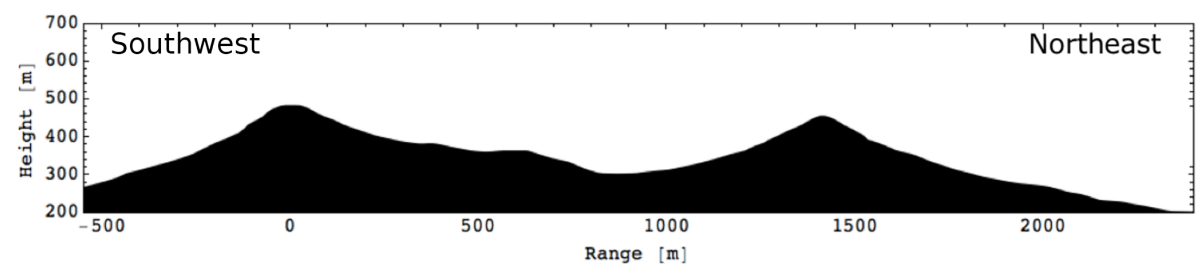

Figure 2. Wind turbine transect oriented $54^{\circ}$ to the north. The wind turbine is located at $0 \mathrm{~m}$ range.

wind turbine. Horizontally, the plane is centred at the turbine location extending $48 \mathrm{~m}$ to each side. Vertically, the plane extends from $30 \mathrm{~m}$ above the height of the turbine foundation to $128 \mathrm{~m}$. The three SRWSs acquired synchronized measurements in this plane along 16 vertical lines (compare Fig. 9b in Vasiljević et al., 2017). Accordingly, all three wind components $(u, v, w)$ were measured. The 312 points were scanned nine times during a $10 \mathrm{~min}$ period, and the system was started manually according to the present wind direction.

For the LRWSs, i.e. the pulsed lidars, the pulse length is the defining factor of the probe length. Considering the relatively short distances of the test site, a $200 \mathrm{~ns}$ pulse was selected. With that pulse, the full-width half maximum of the probe length is about $35 \mathrm{~m}$ and the maximum measurement distance is about $3 \mathrm{~km}$. For two scanners positioned on the northeast ridge (Fig. 1), a measurement trajectory was designed to measure both the turbine inflow and its wake in an almost horizontal plane. The plane is defined by the position of the two scanners and the wind turbine nacelle, resulting in an inclination of $4.7^{\circ}$. The scanners were configured to acquire synchronized measurements in this plane along a line orientated $54^{\circ}$ towards the north with its centre at the wind turbine's nacelle. Due to the synchronous intersection of the two laser beams along this centre line instantaneous, quasi-horizontal wind speeds and directions can be resolved. Measurement points are placed every $20 \mathrm{~m}$ (thus, 50 in total), together with 2450 additional range gates placed next to this line, resulting in a diamond-shaped plane with the dimensions of $500 \mathrm{~m} \times 750 \mathrm{~m}$. The scanners measured this trajectory, called diamond scan, every half an hour for $10 \mathrm{~min}$. A single scan took $25 \mathrm{~s}$, resulting in 24 scans per $10 \mathrm{~min}$ period. An range-height indicator (RHI) scan, a scan with constant azimuth angle and changing elevation angle, toward the northeast along the wind turbine transect (Fig. 1), was carried out by the third LRWS positioned close to the wind turbine. The scan covered elevation angles from -12.5 to $20.5^{\circ}$. In the plane of the RHI scan, a total of 12000 LOS velocities were acquired along 50LOSs. Accordingly, this scan provides a field of LOS velocities. The LOS velocity is the flow component orientated along the lidar's laser beam. During certain periods that are analysed in detail in Sect. 4.2, the wake could be captured with this scan and thus supplements the diamond scan in the vertical direction. 


\section{Data and methods}

\subsection{Determination of inflow conditions}

For analysing the wind turbine wake, detailed information about the inflow to the turbine is a requirement. This raises the question of how the inflow conditions can be described in complex terrain and particularly in this study. The IEC standard (IEC, 2005) provides that a reference measurement should be taken at a position 2-4 rotor diameters upwind from the turbine. Such an approach is not appropriate in complex terrain. Influences of the orography, like the escarpments close to the turbine at the Perdigão site, cause significant perturbations to the flow field over small spatial scales.

Accordingly, inflow measurements should be taken close to the turbine but at positions where the influence of the wind turbine itself to the flow field is insignificant. To describe the turbines influence on the flow field, a model presented by Conway (1995) is chosen. The model shows analytically the influence of the rotor on the flow field under a specific loading of the turbine. Figure 3 shows the influence of the turbine in Perdigão on the free stream velocity $\left(U_{\infty}\right)$ under maximum thrust. The maximal thrust is determined from the turbine's thrust curve and is observed below rated wind speed. We define $R$ as the radius of the wind turbine, $r$ as the radial distance from the symmetry axis of the rotor and $x$ as the distance perpendicular to the rotor. According to this model, measurement sections next to the rotor disk in the diamond scan are selected to represent the inflow conditions to the turbine (compare the two grey sections in Fig. 7a). The wind speed is averaged over two line segments, each $40 \mathrm{~m}$ long and positioned at a distance of $60 \mathrm{~m}$ to the left and right of the wind turbine nacelle. The segments are always aligned perpendicular to the 10 min averaged wind direction calculated over the whole diamond scan plane. Therefore, the position of these segments changes with the wind direction. In terms of the model by Conway (1995), these segments are located in a range $r / R=1.5$ to $r / R=2.5$ and are at $x / R=0$ and thus related to maximal wind speed changes ranging from $0.5 \%$ to $2.5 \%$. However, since the blocking effect of the turbine at the position of the rotor is zero $\left(u / U_{\infty}=1\right)$, no effect on the selected segments is expected. For the case that the segments are not perfectly aligned with the rotor plane, the model shows that the speed-up and the slowdown effects cancel out in the case of the measurement volume being symmetric around the rotor, as it is in our case.

To validate this method, the correlation with the wind turbine supervisory control and data acquisition (SCADA) data are investigated. The SCADA data is available as $10 \mathrm{~min}$ averages for the period of the measurement campaign and include the active power production, the nacelle direction and wind speed measured by the nacelle anemometer. From the measured power production in combination with the turbine's power curve, the rotor-equivalent wind speed $v_{\text {rotor }}$ is derived which represents the wind speed averaged over the

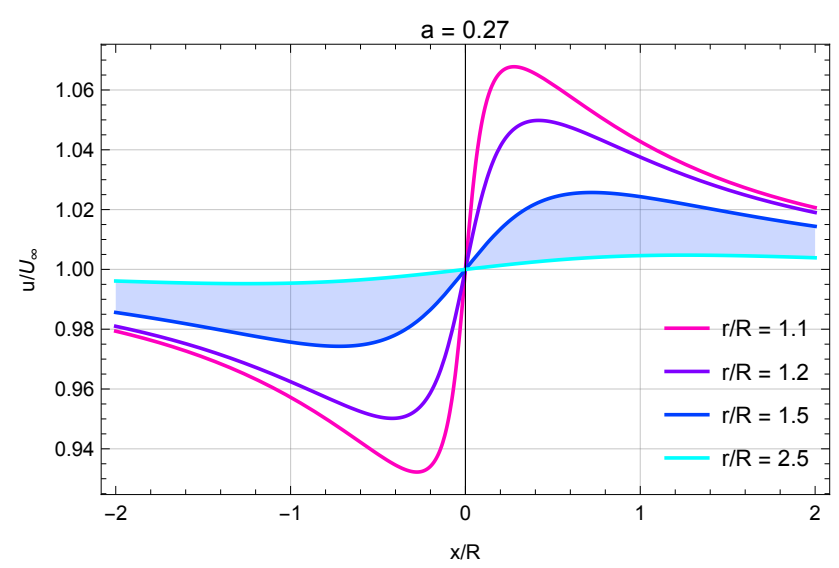

Figure 3. Solution of the actuator disk model by Conway (1995) for an induction factor of $a=0.27$ and different ratios of the distance to the centre line $r$ divided by the radius of the disk $R$. The shaded sector indicates the range in which the inflow measurement volume is located.

entire rotor disk.

$v_{\mathrm{R}}=v_{\mathrm{PC}}(P)$,

where $v_{\mathrm{PC}}$ is interpolated from $1 \mathrm{~m} \mathrm{~s}^{-1}$ binned values of the turbine's power curve. The power curve is corrected for the Perdigão site following the IEC 61400-12 standard (IEC, 2005). An air density of $1.12 \mathrm{~kg} \mathrm{~m}^{-3}$ is assumed resulting from an altitude of $562 \mathrm{~m}$ above mean sea level and an estimated average air temperature of $20^{\circ} \mathrm{C}$. This method is only valid up to $12 \mathrm{~m} \mathrm{~s}^{-1}$, the rated wind speed of the turbine since the power production is constant for higher wind speeds.

The linear correlation of $v_{\mathrm{R}}$ and the wind speed acquired with the WindScanner system shows a good agreement in terms of a high coefficient of determination, $R^{2}=0.96$, and a slope close to 1 (Fig. 4). From the wind speed and direction measured by the diamond scan, a frequency distribution is calculated (Fig. 5). The rose shows the prevailing wind direction west-southwest and northeast, similar to a long-term assessment of the wind conditions at the site (Vasiljević et al., 2017).

\subsection{Data selection}

During the campaign, $663 \mathrm{~h}$ of measurement data was collected by the WindScanner systems: $110 \mathrm{~h}$ with the SRWS system, which was in operation from 8 May until 3 June, and $553 \mathrm{~h}$ with the LRWS, which was in operation from 19 May until 26 June. These numbers are reduced by applying different filtering methods, as explained in Vasiljević et al. (2017). By considering the frequency distribution (Fig. 5), $10 \mathrm{~h}$ of LRWS measurement data is available in the northeastern sector. During these periods data from both the diamond scan and the RHI scan are available. Additionally, $5 \mathrm{~h}$ of wake measurements are available from the SRWS sys- 


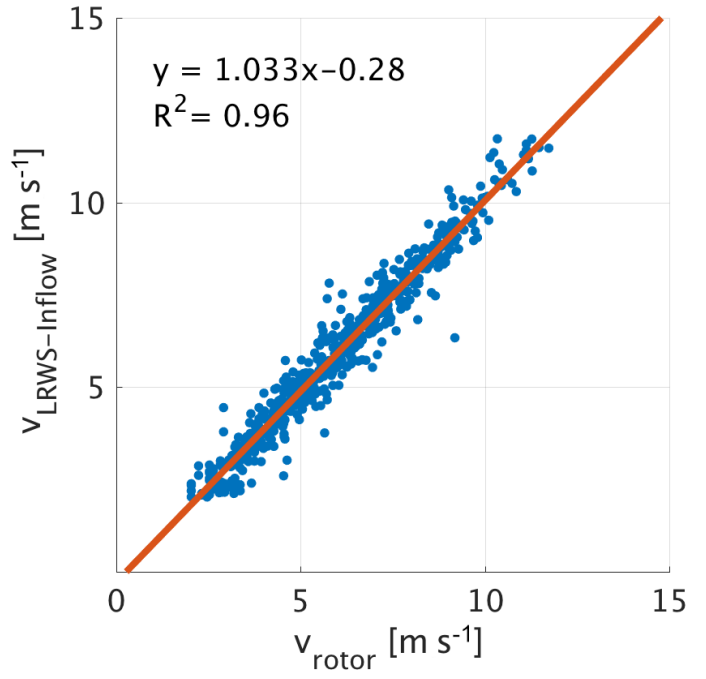

Figure 4. Correlation of the wind speeds derived from the diamond scan to the rotor-equivalent wind speeds. The correlation is derived by 58910 min periods.

tem. Due to technical problems, no simultaneous measurements of the wake with the two WindScanner systems were collected (Vasiljević et al., 2017).

\subsection{Mesoscale flow simulations}

During the period of the campaign, strong radiative forcing was observed that caused significant diurnal changes in the air temperature at ground level. Due to the absence of meteorological stability measurements at the site during the 2015 campaign, simulations with the Weather Research and Forecasting (WRF) model are used to estimate the stability for the period of the campaign. The results are available covering the period between 1 May and 30 June 2015 and are produced with the WRF model version 3.6. For a description of the general WRF model, please refer to Skamarock et al. (2008).

The WRF model simulations are driven using ERAInterim reanalysis datasets (Dee et al., 2011) using the method described in Hahmann et al. (2015) with the MellorYamada-Nakanishi-Niino (MYNN) boundary layer parameterization. A total of three domains are used to downscale the flow field through one-way nesting, covering horizontal grid resolutions from 27 to $3 \mathrm{~km}$ using a $1 / 3$ ratio rule. Time series are extracted from the simulation results at the location of the wind turbine. Thermal stability is inferred from the Obukhov length $L_{\text {mo }}$ computed at the finest $3 \mathrm{~km}$ domain. At sites where stability measurements are available, the WRF model has shown good skill at simulating their climatology (Peña and Hahmann, 2012). However, the complexity of the local terrain is not considered, which can affect the interpretation of the stability length (Weigel et al., 2007; Rotach and Zardi, 2007).

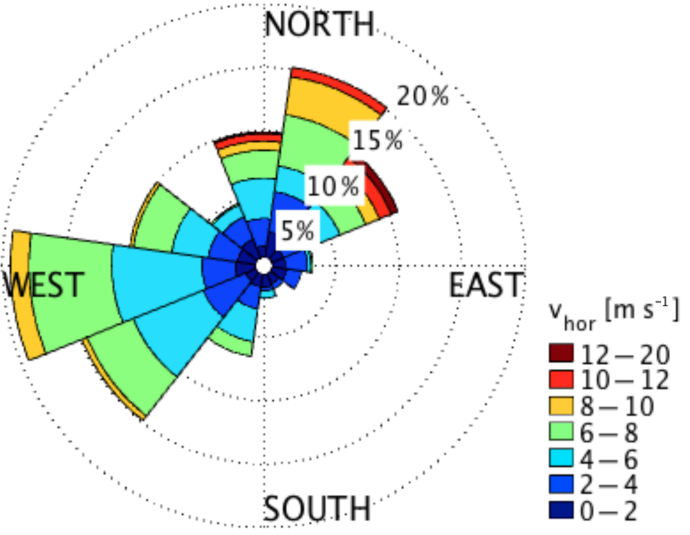

Figure 5. Sector-wise frequency and velocity distribution derived from diamond scan measurements.

The inner domain employs a $244 \times 244 \times 61$ grid, with the highest vertical level set at $50 \mathrm{hPa}$. The orography is generated using USGS $30^{\prime \prime}$ elevation data resampled according to grid resolution. Land-use categories for all domains are based on the CORINE Land Cover 2006 survey (CLC, 2006). For a detailed description of the simulation setup, please refer to Hahmann et al. (2017).

\subsection{Atmospheric stratification at the wind turbine location}

The WRF results show prevailingly stable atmospheric conditions during the night and unstable conditions during the day. Neutral conditions are present during transitions. We derive the stability from the Obukhov length using the following classification: stable $1 / L_{\mathrm{mo}}>0.01$, neutral $0.01>1 / L_{\mathrm{mo}}>-0.01$, unstable $1 / L_{\mathrm{mo}}<-0.01-$ similar to Muñoz-Esparza et al. (2012). The distribution of different stabilities over the rotor-equivalent wind speed shows that both stable and unstable stratification are well represented, while the neutral stratification is infrequently represented (Fig. 6).

\section{Results}

\subsection{Wake deficit and wake structure}

Given the reference inflow wind speed obtained by the diamond scan, wake deficit profiles can be calculated in the measurement plane. These are based on horizontal wind speed retrievals from the dual-Doppler measurements. Deficit profiles are calculated at 1, 2 and 3 rotor diameters $(D)$ downstream of the wind turbine, where the velocity deficit at each point $i$ of a profile is defined as

$\Delta V_{i}=\left(1-\frac{V_{i}}{V_{\text {inflow }}}\right)$. 


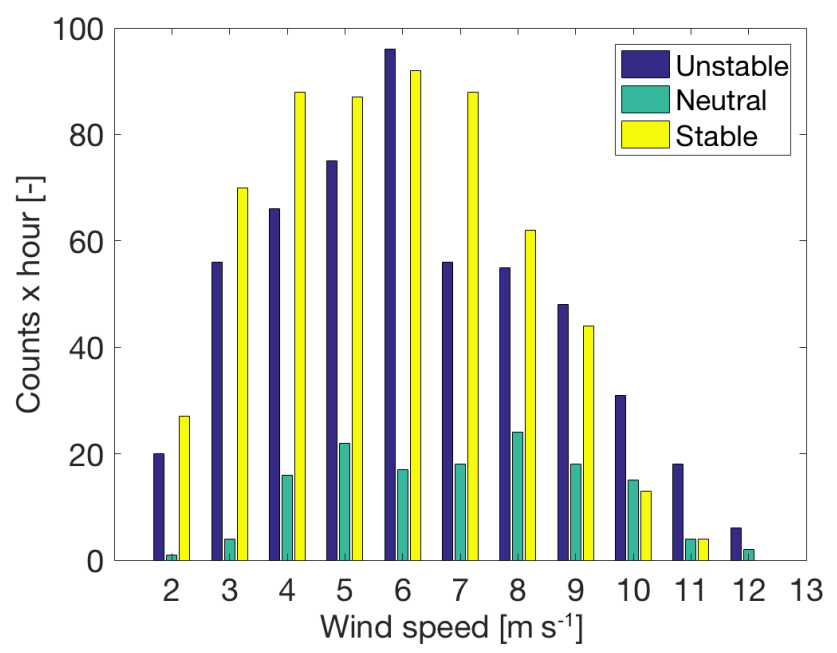

Figure 6. Stratification of the observations during the months of May and June 2015. The wind speed is estimated from the rotorequivalent wind speed.

An example of a $10 \mathrm{~min}$ average period from 06:49 to 06:59 UTC, 7 June 2015, is shown in Fig. 7a. The profile extracted at $1 D$ distance (Fig. 7b) shows a deficit with a local minimum in the wake centre, caused by a lowerenergy extraction around the nacelle. With increasing distance, this minimum disappears and the maximum deficit decreases from over $70 \%$ to $50 \%$.

The averaged wake deficit for all available $10 \mathrm{~min}$ periods in sectors to towards the northeast and southwest $\left(54 \pm 15^{\circ}\right.$ and $234 \pm 15^{\circ}$ ) are calculated. The average maximum deficits are $53 \%(55 \%)$ at $1 \mathrm{D}$ downstream for the northeastern (southwestern) sectors. For downstream distances of $2 D$ and $3 D$, in some periods the wake moves above or below the diamond scan plane, and therefore, the wake is not entirely captured by the diamond scan. This misalignment means that deficit profiles measured with the diamond scan may not capture the wake centre or the maximum wake deficit. Nevertheless, close to the turbine, the wake misalignment with the diamond scan is expected to be small, which allowed calculating an average deficit for specific sectors at a distance of one rotor diameter. Consequently, only selected periods can be investigated over the entire length of the diamond scan.

\subsection{Wake propagation}

The wind turbine wake propagation is investigated for wind directions in a $30^{\circ}$ sector centred around the wind turbine transect $\left(54^{\circ}\right)$. This sector is covered by both the diamond scan and the transect scan which makes a combined use of the scans possible. Moreover, this transect is aligned with the centre of the SRWS wake scan. The investigation of $10 \mathrm{~min}$ averaged scans reveals significant vertical displacements of the wake. Considering both the state of the atmosphere cap-
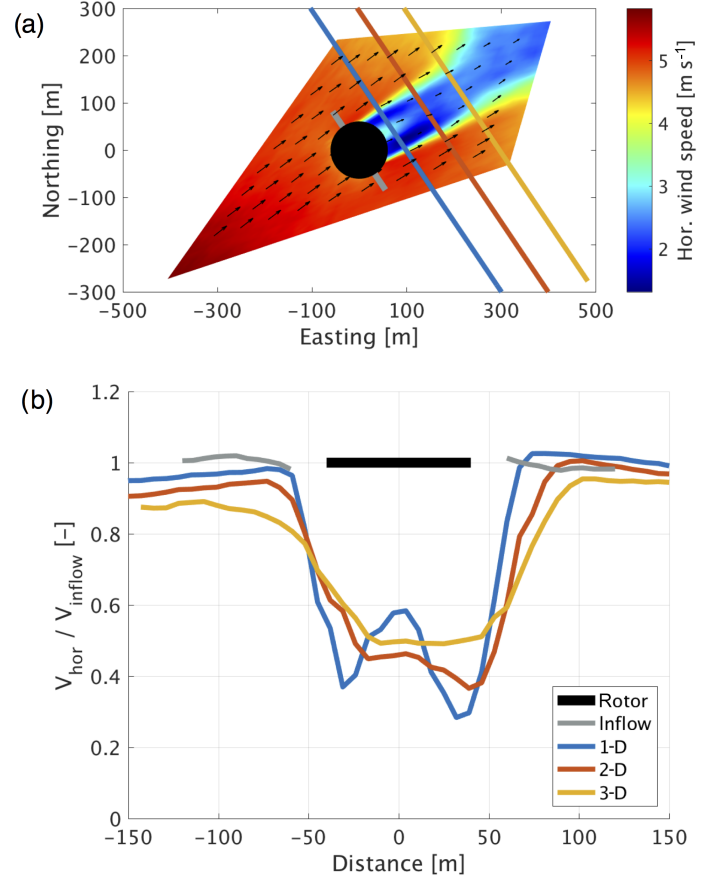

Figure 7. Wind turbine wake deficit observed with the diamond scan (10 min averaged period measured on 7 June 2015 from 06:18 to 06:28): (a) diamond scan with lines indicating the position of deficit profiles; (b) wake deficit profiles. The average tip speed ratio during this period is $\lambda=6.7$, and the power coefficient is $c_{\mathrm{p}}=1.7 \times$ $10^{-4}$.

Table 1. Wake categorization according to stratification (the stratification is defined by the Obukhov length: stable $1 / L_{\text {mo }}>0.01$, neutral $0.01>1 / L_{\mathrm{mo}}>-0.01$, unstable $1 / L_{\mathrm{mo}}<-0.01$ ). Periods with atmospheric waves are identified by visual inspection of the transect scans.

\begin{tabular}{lll}
\hline Case & Stratification & Wake advection \\
\hline 1 & stable + atmospheric wave & downwards \\
2 & stable & straight \\
3 & neutral & straight \\
4 & unstable & upwards \\
\hline
\end{tabular}

tured by the transect scan and the WRF simulation results, four different cases are identified (see Table 1).

Examples for each case are presented in Fig. 9. The first two cases (panels a and b) are observed between sunset and sunrise during stable atmospheric conditions. These periods are categorized by distinct atmospheric layers of different wind speeds and directions. The transect scans for some nocturnal periods show an atmospheric wave pattern which interacts with the wake, displacing it downwards (case 1, Fig. 9a) in the direction of the leeward ridge slope, causing strong displacements of the wake centre. The wake leaves the plane of the diamond scan after one or two rotor diameters down- 
(a)

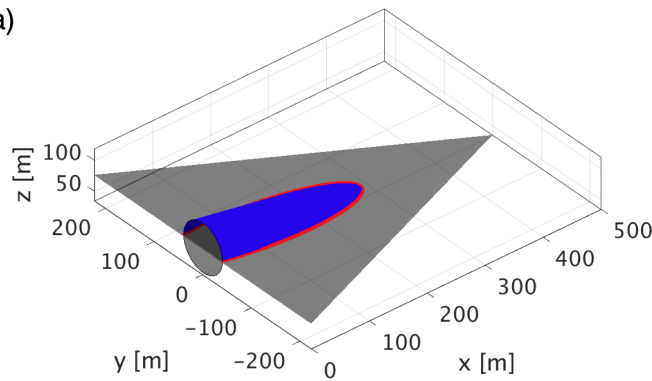

(b)

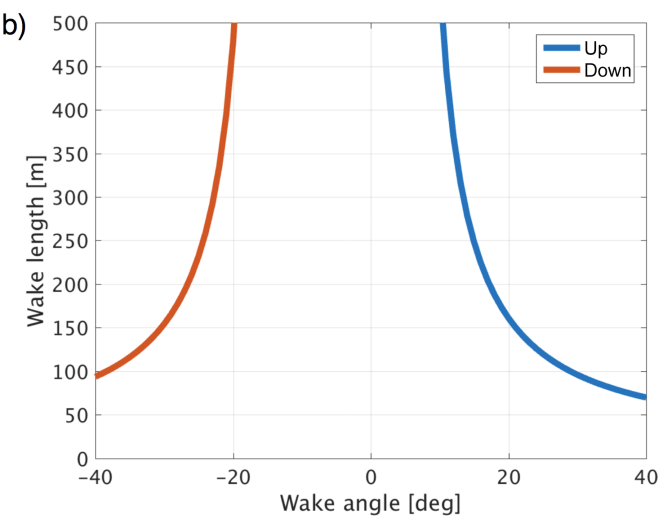

Figure 8. Wake cross section model: (a) model schematic for a negative vertical wake angle of $-23^{\circ}$ (black plane: one half of the diamond scan plane; blue plane: cone section representing the wake; red line: cross section; black circle: rotor plane); (b) derived length of the wake cross section in the diamond scan for different wake angles with a wake expansion angle of $\Theta=10^{\circ}$. The asymmetry of the model results from the negatively inclined scanning plane.

stream and continues to propagate above the plane of the transect scan.

To relate the wake shapes in the diamond scan to a wake displacement, the cross-sectional area of an idealized wake and the diamond scan plane are geometrically modelled. The model, which contains code originally presented by Calinon (2009), represents the wake by a cone with an off-axis opening angle of $\Theta=10^{\circ}$ corresponding to the wake expansion determined at $2 D$ distance for the period depicted in Fig. 9b (case 2). By varying the vertical angle of the cone, the length of the cross section visible in the diamond scan is derived. The model shows that wakes stay within the dimensions of the diamond scan plane for vertical displacement angles from 10 to $-19^{\circ}$; see Fig. 8 . For larger displacements, only a cross section of wakes is visible.

The categorization and the geometrical model are applied to all periods for which the transect scan and the diamond scan are available and the wind direction falls in the relevant sector. The wake length is determined from contour plots of the diamond scan, and the transect scan determines the direction of vertical displacement. In total 21 periods are categorized in an upwards, downwards or straight wake propagation in relation to the atmospheric stability; see Fig. 10a.
Two of the 21 periods show a wake centre displaced downwards and 6 a straight propagation of the wake, and the remaining 14 periods show an upward-moved wake centre. The wake propagates straight or downwards depending on the presence of an atmospheric wave during stable conditions. Displacements upwards are observed mainly during unstable conditions. Inconsistencies in the categorization and calculated stability occur in the evening at around 18:00, where displacements downwards are observed and the WRF simulation shows neutral conditions. A reason for this may be that the WRF simulation has problems resolving the exact time of the transition from unstable to neutral conditions. For clarification, direct measurements of the stability are necessary. However, the simulations agree in general with the categorization and show an expected diurnal cycle for the period of the campaign. Neutral conditions are expected at the transition from stable to unstable periods (or vice versa). The cross-sectional model shows wake angles from 21 to $29^{\circ}$ during stable conditions and angles of up to $-28^{\circ}$ in combination with the presence of an internal wave (Fig. 10b).

Results of the of the short-range WindScanner scan at one rotor diameter distance indicate an equal behaviour of the wake propagation. Periods are observed where the wake centre is moved downwards or lifted upwards. In the case of a downward-moved wake, it is observed that there is no clear distinction between the wake and the flow field under the rotor (Fig. 11b). The upward-moved case, on the other hand, shows clearly the flow passing between the ground and the rotor disc. The short-range WindScanner system could provide only a small amount of wake measurements. Limitations were a small scanning plan, which only allowed us to capture the wake for a narrow sector of wind directions, and technical problems with the system.

\section{Summary and conclusions}

Measurement data from six scanning lidars have been analysed with the purpose of describing the wind turbine wake propagation in complex terrain. The data, recorded in the summer of 2015, were collected at a site with highly complex orography in the centre of Portugal, near the town of Perdigão. The analysis focuses on the vertical wake propagation under different atmospheric stability conditions, whose influence is generally ignored in computational flow simulations, namely those performed for wind farm layout design. The combined analysis of a horizontal scanning plane, centred around the wind turbine, and a transect scan of radial wind speeds in that sector revealed strong vertical wake angles. In total, four different wake cases are identified that show, among horizontal wake propagation, strong displacements upwards and downwards of the wake during stable and unstable atmospheric conditions. These displacements are caused by the flow field that is influenced by the atmospheric stability and the orographic structure of the terrain 
(a)

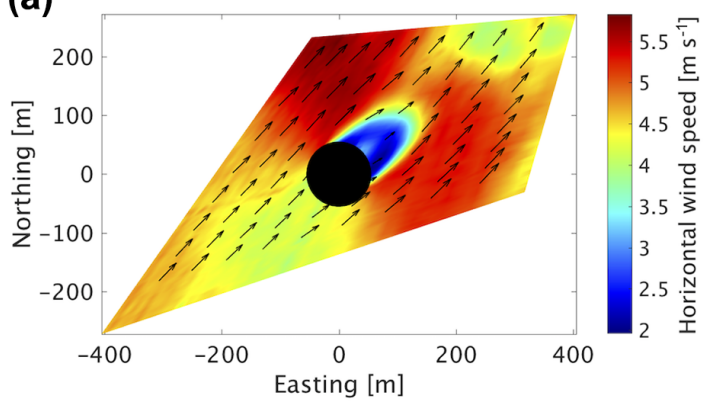

(b)

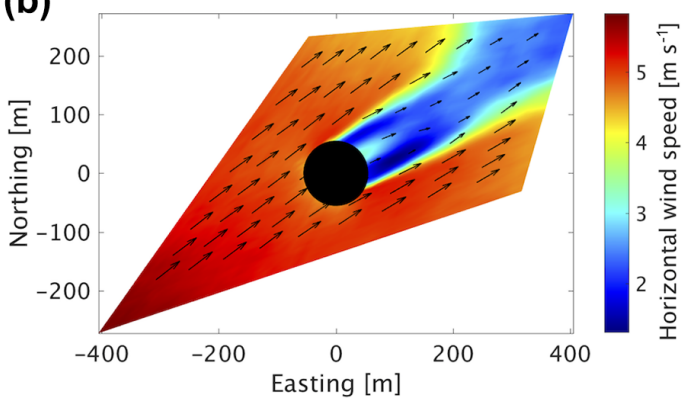

(c)

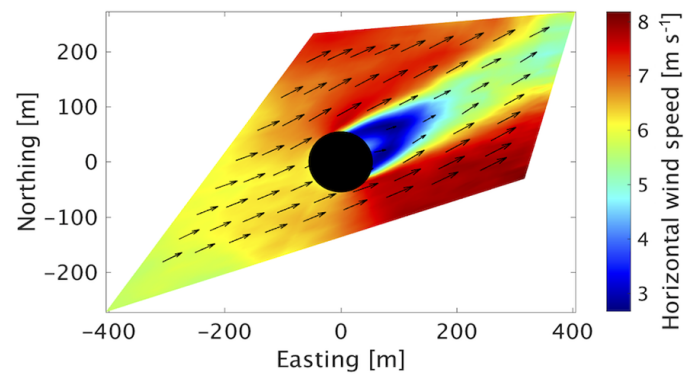

(d)

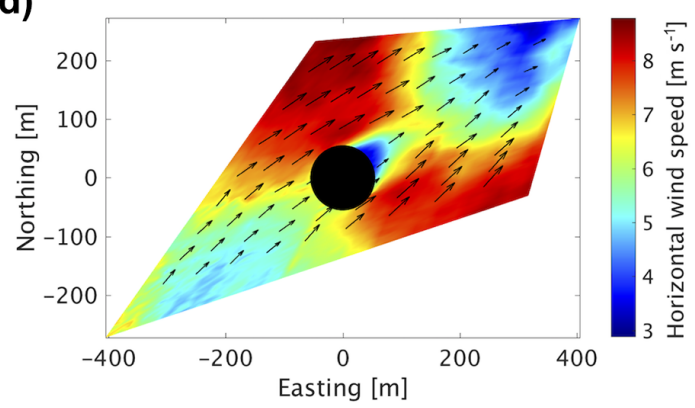

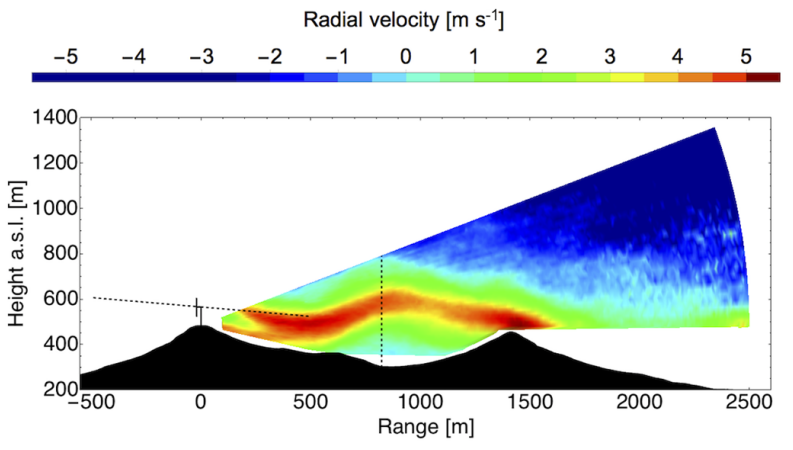
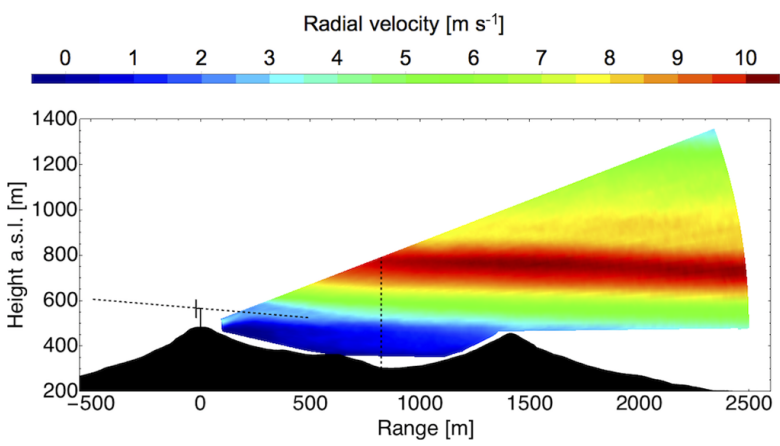

Radial velocity $\left[\mathrm{m} \mathrm{s}^{-1}\right]$

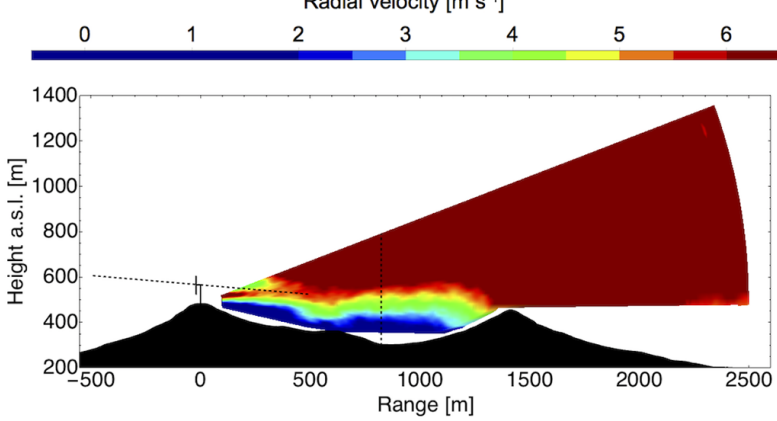

Radial velocity $\left[\mathrm{m} \mathrm{s}^{-1}\right]$

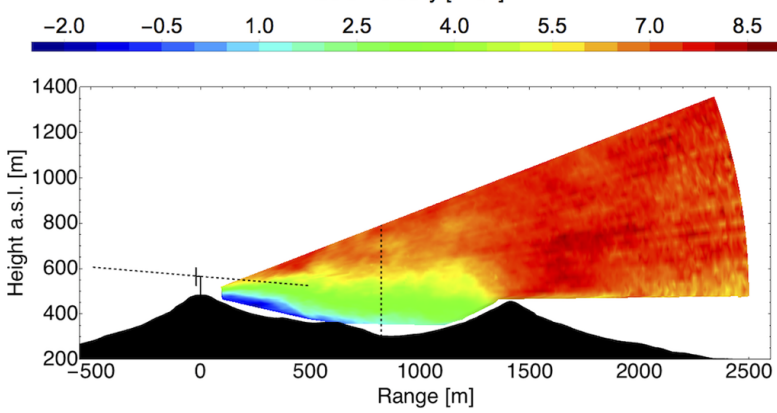

Figure 9. Observed wake cases with the diamond scan (left) and transect scan (right). (a) Downwards-displaced wake, stable atmospheric conditions + atmospheric wave; (b) no displacement, stable atmospheric conditions; (c) no displacement, neutral atmospheric conditions; (d) upwards-displaced wake, unstable atmospheric conditions (measurements of example periods taken (a) 02:52-03:02 UTC, 9 June 2015, (b) 06:18-06:28 UTC, 7 June 2015, (c) 22:20-22:30 UTC, 10 June 2015, (d) 11:16-11:26 UTC, 10 June 2015).

around the turbine. By including data from a WRF simulation that provides estimates of the atmospheric stability in terms of the Obukhov length, a correlation between wake angles and stability emerges. During unstable conditions, the wake is lofted up by up to $29^{\circ}$. During stably stratified condi- tions, wakes follow the terrain, resulting in downward wake angles reaching $-28^{\circ}$. Under neutral conditions, the wake propagates approximately horizontally despite the complex orography. Wake deficits of $70 \%$ are measured at $1 D$ distance, decreasing to $50 \%$ at $3 \mathrm{D}$ distance. Differences in 
(a)

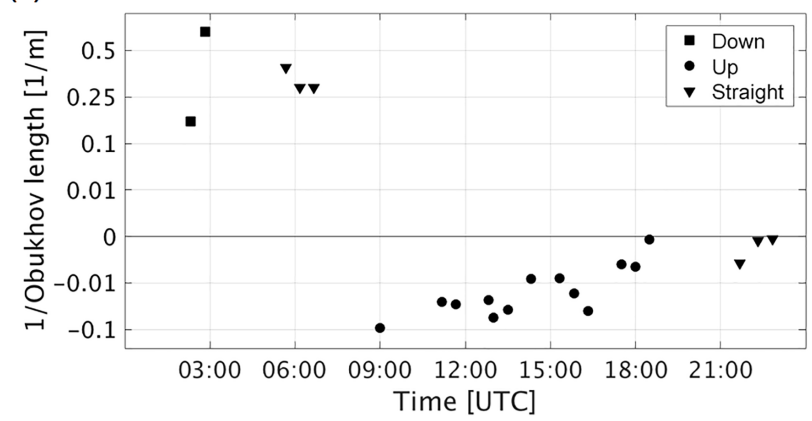

(b)

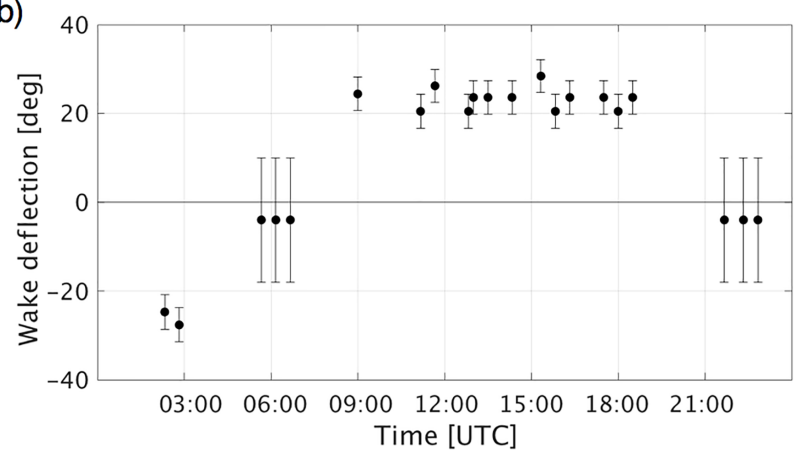

Figure 10. Wake displacements as a function of the time of the day: (a) direction of displacement relative to one over the Obukhov length; (b) wake deflection angles according to the cross-sectional model. The error indicates the sensitivity to the wake expansion angle for changes of $\Delta \Theta= \pm 2^{\circ}$. For periods with a straight wake propagation (case 3), the error indicates the range of $\Theta$ for which wakes are fully covered by the diamond scan.

wake characteristics observed with the scanning trajectories of this study arise from a combination of angles between wake and scanning plane, atmospheric conditions, and the operational state of the turbine. With the present dataset, it is not possible to isolate the effect of these factors.

This study shows that wake propagation is highly complex and strongly depends on the stability conditions and the terrain orography. The question "Does the wake follow the terrain?" is answered: in some stable conditions the wake does follow the terrain, but in the majority of cases observed here, the wake does not follow the terrain. However, the wake could not be observed over the full vertical range with the scanning trajectories of this campaign as the designed trajectories addressed several scientific objectives at the same time (see Vasiljević et al., 2017). For future investigations of the wind turbine wake propagation in complex terrain, it is recommended to design scanning trajectories so that they cover a wider vertical range and to ideally focus only on a single scientific objective. Furthermore, a nacelle-mounted spinner lidar (Mikkelsen et al., 2010) could provide more detailed information about the inflow to the turbine, as this investigation showed that it is challenging to describe the inflow in complex terrain.
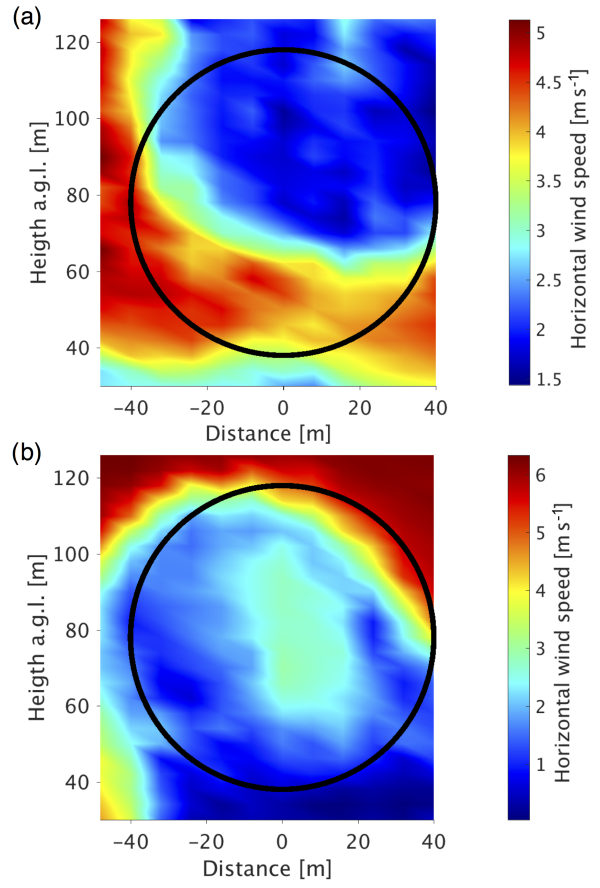

Figure 11. Short-range WindScanner wake measurements: (a) upward-moved wake (10 min period from 19:20 to 19:30 UTC, 11 May 2015) and (b) downward-moved wake (10 min period from 00:50 to 01:00 UTC, 12 May 2015); further examples are presented in Hansen et al. (2016). Black circle: projected rotor disc.

Data availability. The WRF simulation data can be shared on request. Moreover, almost identical WRF simulation data will be published by the NEWA (New European Wind Atlas) project. The WindScanner data will be available under the following DOI: https: //doi.org/10.11583/DTU.7098536 (Vasiljevic et al., 2018).

Author contributions. RM analysed the data with support from $\mathrm{NV}$ and KSH. RM developed the method used to determine the inflow to the wind turbine and characterized the wake behaviour with the help and supervision of JM and KSH. NV and JM designed the field experiment, with feedback from $\mathrm{KSH}$, and executed it. $\mathrm{ANH}$ performed the WRF simulation. RM wrote the main body of paper with input from all authors. All authors contributed with critical feedback on this research.

Competing interests. The authors declare that they have no conflict of interest.

Special issue statement. This article is part of the special issue "Flow in complex terrain: the Perdigão campaigns (ACP/WES/AMT inter-journal SI)". It is not associated with a conference. 
Acknowledgements. All authors thank Carlos Rodrigues for his great input to this research. We also acknowledge the work of José Laginha Palma and Jose Carlos Matos. Their great contribution during all phases of the field campaign helped to make the campaign a success. We also thank Mike Courtney for his work in the planning and design process of the campaign. We would like to thank Nikolas Angelou for the operation of the short-range WindScanner system and his help with the data processing and Guillaume Lea, who helped to process the data of the long-range WindScanner system. Furthermore, the authors acknowledge the FarmOpt project for the financial support for the Perdigão 2015 field campaign. FarmOpt (http://energiforskning.dk/en/projects/detail? program =All\&teknologi=All\&field_bevillingsaar_value $=\&$ start $=$ $\&$ slut $=\&$ field_status_value $=$ All \&keyword=FarmOpt $\&$ page $=0$, last access: 13 September 2018) was funded by the Danish Energy Technology Development and Demonstration Program (EUDP), project no. 64013-0405. We thank the Danish Energy Agency for funding through the New European Wind Atlas project.

Edited by: Julie Lundquist

Reviewed by: Michele Guala and one anonymous referee

\section{References}

Abkar, M. and Porté-Agel, F.: Influence of atmospheric stability on wind-turbine wakes: A large-eddy simulation study, Phys. Fluids, 27, 035 104, 2015.

Aitken, M. L. and Lundquist, J. K.: Utility-scale wind turbine wake characterization using nacelle-based long-range scanning lidar, J. Atmos. Ocean. Tech., 31, 1529-1539, 2014.

Aitken, M. L., Kosović, B., Mirocha, J. D., and Lundquist, J. K.: Large eddy simulation of wind turbine wake dynamics in the stable boundary layer using the Weather Research and Forecasting Model, J. Renew. Sustain. Ener., 6, 033137, https://doi.org/10.1063/1.4885111, 2014.

Barthelmie, R. J., Frandsen, S. T., Nielsen, M., Pryor, S., Rethore, P.-E., and Jørgensen, H. E.: Modelling and measurements of power losses and turbulence intensity in wind turbine wakes at Middelgrunden offshore wind farm, Wind Energy, 10, 517-528, 2007.

Bhaganagar, K. and Debnath, M.: The effects of mean atmospheric forcings of the stable atmospheric boundary layer on wind turbine wake, J. Renew. Sustain. Ener., 7, 013124, https://doi.org/10.1063/1.4907687, 2015.

Bingöl, F., Trujillo, J. J., Mann, J., and Larsen, G. C.: Fast wake measurements with LiDAR at Ris $\varnothing$ test field, in: IOP Conference Series: Earth and Environmental Science, vol. 1, IOP Publishing, Bristol, England, 2008.

Bingöl, F., Mann, J., and Larsen, G. C.: Light detection and ranging measurements of wake dynamics part I: one-dimensional scanning, Wind Energy, 13, 51-61, 2010.

Bodini, N., Zardi, D., and Lundquist, J. K.: Threedimensional structure of wind turbine wakes as measured by scanning lidar, Atmos. Meas. Tech., 10, 2881-2896, https://doi.org/10.5194/amt-10-2881-2017, 2017.

Bustamante, A., Vera-Tudela, L., and Kühn, M.: Evaluation of wind farm effects on fatigue loads of an individual wind turbine at the EnBW Baltic 1 offshore wind farm, in: J. Phys. Conf. Ser., 625, 012020, IOP Publishing, Bristol, England, 2015.
Calinon, S.: Robot Programming by Demonstration: A Probabilistic Approach, EPFL/CRC Press, ePFL Press ISBN 978-2-94022231-5, CRC Press ISBN 978-1-4398-0867-2, 2009.

CLC: CORINE Land Cover $100 \mathrm{~m}$ raster data, European Environmental Agency (EEA), available at: https://www.eea.europa.eu/ data-and-maps/data/clc-2006-raster-4 (last access: 13 September 2018), 2006.

Conway, J. T.: Analytical solutions for the actuator disk with variable radial distribution of load, J. Fluid Mech., 297, 327-355, 1995.

Dee, D. P., Uppala, S., Simmons, A., Berrisford, P., Poli, P., Kobayashi, S., Andrae, U., Balmaseda, M., Balsamo, G., Bauer, P., Bechtold, P., Beljaars, A. C. M., van de Berg, L., Bidlot, J., Bormann, N., Delsol, C., Dragani, R., Fuentes, M., Geer, A. J., Haimberger, L., Healy, S. B., Hersbach, H., Hólm, E. V., Isaksen, L., Kållberg, P., Köhler, M., Matricardi, M., McNally, A. P., Monge-Sanz, B. M., Morcrette, J.-J., Park, B.-K., Peubey, C., de Rosnay, P., Tavolato, C., Thépaut, J.-N., and Vitart, F.: The ERA-Interim reanalysis: Configuration and performance of the data assimilation system, Q. J. Roy. Meteor. Soc., 137, 553-597, 2011.

Englberger, A. and Dörnbrack, A.: Impact of the Diurnal Cycle of the Atmospheric Boundary Layer on Wind-Turbine Wakes: A Numerical Modelling Study, Bound.-Lay. Meteorol., 166, 1-26, 2017.

Hahmann, A., Witha, B., Rife, D., Frouzakis, N., Junk, C., Sile, T., Baltscheffsky, M., Dörenkämper, M., Ezber, Y., Bustamante, E., Gonzalez-Rouco, F., Mentes, S., Navarro, J., Söderberg, S., and Unal, Y.: Description of the Probabilistic Wind Atlas Methodology, Deliverable D3.1, NEWA - New European Wind Atlas, Denmark, 2017.

Hahmann, A. N., Vincent, C. L., Peña, A., Lange, J., and Hasager, C. B.: Wind climate estimation using WRF model output: Method and model sensitivities over the sea, Int. J. Climatol. 35, 3422-3439, 2015.

Hansen, K., Larsen, G., Menke, R., Vasiljević, N., Angelou, N., Feng, J., Zhu, W., Vignaroli, A., W, W. L., Xu, C., and Shen, W.: Wind turbine wake measurement in complex terrain, J. Phys. Conf. Ser., 753, 032013, https://doi.org/10.1088/17426596/753/3/032013, 2016.

Herges, T., Maniaci, D., Naughton, B., Mikkelsen, T., and Sjöholm, M.: High resolution wind turbine wake measurements with a scanning lidar, in: EWEA Wake Conference, J. Phys.-Conf. Ser., 854, 012021, 2017.

IEC: IEC 61400-12-1 - Part 12-1: Power performance measurements of electricity producing wind turbines, Tech. rep., International Electrotechnical Commission, 2005.

Iungo, G. and Porté-Agel, F.: Measurement procedures for characterization of wind turbine wakes with scanning Doppler wind $\mathrm{Li}$ DARs, Adv. Sci. Res., 10, 71-75, 2013.

Käsler, Y., Rahm, S., Simmet, R., and Kühn, M.: Wake measurements of a multi-MW wind turbine with coherent long-range pulsed Doppler wind lidar, J. Atmos. Ocean. Tech., 27, 15291532, 2010.

Krishnamurthy, R., Choukulkar, A., Calhoun, R., Fine, J., Oliver, A., and Barr, K.: Coherent Doppler lidar for wind farm characterization, Wind Energy, 16, 189-206, 2013.

Machefaux, E., Larsen, G. C., Troldborg, N., Hansen, K., Angelou, N., Mikkelsen, T., and Mann, J.: Investigation of wake interaction 
using full-scale lidar measurements and large eddy simulation, Wind Energy, 19, 1535-1551, 2016.

Mann, J., Angelou, N., Arnqvist, J., Callies, D., Cantero, E., Arroyo, R. C., Courtney, M., Cuxart, J., Dellwik, E., Gottschall, J., Ivanell, S., Kühn, P., Lea, G., Matos, J. C., Palma, J. M. L. M., Pauscher, L., Peña, A., Rodrigo, J. S., Söderberg, S., Vasiljevic, N., and Rodrigues, C. V.: Complex terrain experiments in the New European Wind Atlas, Philos. T. R. Soc. A, 375, 20160101, https://doi.org/10.1098/rsta.2016.0101, 2017.

Mikkelsen, T., Mann, J., Courtney, M., and Sjöholm, M.: Windscanner: 3-d wind and turbulence measurements from three steerable Doppler lidars, in: IOP conference series: earth and environmental science, 1, 012018, IOP Publishing, Bristol, England, 2008.

Mikkelsen, T., Hansen, K. H., Angelou, N., Sjöholm, M., Harris, M., Hadley, P., Scullion, R., Ellis, G., and Vives, G.: Lidar wind speed measurements from a rotating spinner, in: 2010 European Wind Energy Conference and Exhibition, Proc. European Wind Energy Conference, Warsaw, Poland, 1-6, 2010.

Mirocha, J., Kosovic, B., Aitken, M., and Lundquist, J.: Implementation of a generalized actuator disk wind turbine model into the weather research and forecasting model for large-eddy simulation applications, J. Renew. Sustain. Ener., 6, 013104, https://doi.org/10.1063/1.4861061, 2014.

Mirocha, J. D., Rajewski, D. A., Marjanovic, N., Lundquist, J. K., Kosović, B., Draxl, C., and Churchfield, M. J.: Investigating wind turbine impacts on near-wake flow using profiling lidar data and large-eddy simulations with an actuator disk model, J. Renew. Sustain. Ener., 7, 043143, https://doi.org/10.1063/1.4928873, 2015.

Muñoz-Esparza, D., Cañadillas, B., Neumann, T., and van Beeck, J.: Turbulent fluxes, stability and shear in the offshore environment: Mesoscale modelling and field observations at FINO1, J. Renew. Sustain. Ener., 4, 063136, https://doi.org/10.1063/1.4769201, 2012.

Peña, A. and Hahmann, A. N.: Atmospheric stability and turbulence fluxes at Horns Rev - an intercomparison of sonic, bulk and WRF model data, Wind Energy, 15, 717-731, 2012.

Rhodes, M. E. and Lundquist, J. K.: The effect of wind-turbine wakes on summertime US midwest atmospheric wind profiles as observed with ground-based Doppler lidar, Bound.-Lay. Meteorol., 149, 85-103, 2013.

Rotach, M. W. and Zardi, D.: On the boundary-layer structure over highly complex terrain: Key findings from MAP, Q. J. Roy. Meteor. Soc., 133, 937-948, https://doi.org/10.1002/qj.71, 2007.

Skamarock, W. C., Klemp, J. B., Dudhia, J., Gill, D. O., Barker, D. M., Duda, M. G., Huang, X.-Y., Wang, W., and Powers, J. G.: A Description of the Advanced Research WRF Version 3, Technical Note NCAR/TN-475+STR, National Center for Atmospheric Research, Boulder CO USA, 113 pp., 2008.

Smalikho, I., Banakh, V., Pichugina, Y., Brewer, W., Banta, R., Lundquist, J., and Kelley, N.: Lidar investigation of atmosphere effect on a wind turbine wake, J. Atmos. Ocean. Tech., 30, 2554 $2570,2013$.
Thomsen, K. and Sørensen, P.: Fatigue loads for wind turbines operating in wakes, J. Wind Eng. Ind. Aerod., 80, 121-136, 1999.

Troen, I. and Petersen, E. L.: European Wind Atlas, Ris $\varnothing$ National Laboratory, 1989.

Trujillo, J.-J., Bingöl, F., Larsen, G. C., Mann, J., and Kühn, M.: Light detection and ranging measurements of wake dynamics. Part II: two-dimensional scanning, Wind Energy, 14, 61-75, 2011.

Vasiljevic, N.: A time-space synchronization of coherent Doppler scanning lidars for 3D measurements of wind fields, $\mathrm{PhD}$ thesis, Technical University of Denmark, Department of Wind Energy, Roskilde, Denmark, 2014.

Vasiljević, N., Angleou, N., Menke, R., Lea, G., Mann, J., Courtney, M., Palma, J. L., and Matos, J. C.: Perdigão2015: multi-lidar flow mapping over the complex terrain site including the wind turbine inflow and wake measurements, https://doi.org/10.11583/DTU.7098536, 2018.

Vasiljević, N., Lea, G., Courtney, M., Cariou, J.-P., Mann, J., and Mikkelsen, T.: Long-range WindScanner system, Remote Sens. 8, 896, https://doi.org/10.3390/rs8110896, 2016.

Vasiljević, N., L. M. Palma, J. M., Angelou, N., Carlos Matos, J., Menke, R., Lea, G., Mann, J., Courtney, M., Frölen Ribeiro, L., and M. G. C. Gomes, V. M.: Perdigão 2015: methodology for atmospheric multi-Doppler lidar experiments, Atmos. Meas. Tech., 10, 3463-3483, https://doi.org/10.5194/amt-103463-2017, 2017.

Vollmer, L., van Dooren, M., Trabucchi, D., Schneemann, J., Steinfeld, G., Witha, B., Trujillo, J., and Kühn, M.: First comparison of LES of an offshore wind turbine wake with dual-Doppler lidar measurements in a German offshore wind farm, in: J. Phys. Conf. Ser., vol. 625, IOP Publishing, Bristol, England, 2015.

Vollmer, L., Steinfeld, G., Heinemann, D., and Kühn, M.: Estimating the wake deflection downstream of a wind turbine in different atmospheric stabilities: an LES study, Wind Energ. Sci., 1, 129141, https://doi.org/10.5194/wes-1-129-2016, 2016.

Weigel, A. P., Chow, F. K., and Rotach, M. W.: The effect of mountainous topography on moisture exchange between the "surface" and the free atmosphere, Bound.-Lay. Meteorol., 125, 227-244, https://doi.org/10.1007/s10546-006-9120-2, 2007.

Witze, A.: World's largest wind-mapping project spins up in Portugal, Nature, 542, 282-283, 2017. 